\title{
A MEDIAÇÃo COMO INSTRUMENTO DE PACIFICAÇÃO SOCIAL NOS CONFLITOS FUNDIÁRIOS URBANOS
}

\author{
Marcus Filipe Freitas Coelho ${ }^{85}$ \\ Isabela Rocha Laragnoit De Martino ${ }^{86}$
}

Recebido em: 28/03/2019

Aprovado em: 18/09/2019

\begin{abstract}
RESUMO
O presente artigo aborda os conflitos fundiários urbanos em que, via de regra, estão presentes, de um lado, o direito à moradia e, do outro, o direito ao meio ambiente - ecologicamente equilibrado, ambos assegurados por diversos tratados que o Brasil é signatário, bem como pela Constituição Federal. Deste modo, considerando que há uma grave necessidade de ponderação entre tais direitos no caso concreto, analisou-se a possibilidade de aplicação do instituto da mediação de tais conflitos, em especial no âmbito da regularização fundiária no afã de assegurar uma solução mais razoável e justa para todos os envolvidos. Em relação aos procedimentos metodológicos, esta pesquisa possuiu abordagem qualitativa, com base descritiva e caráter exploratório, tendo sido realizado levantamento bibliográfico para a elaboração do aporte teórico disposto ao longo do trabalho. Por fim, verificou-se que o referido meio alternativo de resolução de conflitos é essencial para a garantia dos direitos fundamentais em questão.
\end{abstract}

Palavras-chave: Mediação. Regularização fundiária. Moradia. Meio ambiente.

\section{INTRODUÇÃO}

A política de desenvolvimento e expansão urbana integra hodiernamente o planejamento estratégico das cidades e constitui elemento imprescindível para a melhoria do meio ambiente artificial. O presente artigo trata da importância da regularização fundiária urbana, instituto jurídico e político previsto no artigo $4^{\circ}$, inciso $\mathrm{V}$, alínea $q$, do Estatuto da Cidade. Referido instrumento da ordem urbanística contribui para o alcance do direito

\footnotetext{
${ }^{85}$ Mestre em Direito Ambiental pela Universidade Católica de Santos (2017-2018). Bacharel em Direito pela Faculdade de Direito de São Bernardo do Campo (2016). Professor de curso preparatório para o Exame de Ordem dos Advogados do Brasil. Advogado com experiência profissional na área Societária.

${ }^{86}$ Mestranda em Direito Ambiental e Sustentabilidade pela Universidade Católica de Santos. Graduada em Direito pela Universidade Católica de Santos (2015). Advogada.
} 
humano constitucional à moradia digna, servindo, ainda, como instrumento de combate às desigualdades sociais, haja vista que a função social das cidades, além de tantas outras finalidades, compreende a de implementar o direito fundamental à habitação.

O direito à moradia é uma necessidade primordial do ser humano, sendo certo que a habitação é indicador social e econômico de aferição da qualidade de vida. A eliminação das desigualdades sociais extremas sobrepõe-se ao tradicional conceito do direito de propriedade e de posse. Incorporam-se os fundamentos dos direitos humanos no âmbito do direito ambiental das cidades.

Desde o início de sua urbanização, o Brasil enfrenta sérios problemas relacionados à moradia e à propriedade urbana e rural. $\mathrm{O}$ desequilíbrio socioeconômico que decorre dos processos de exclusão social e segregação espacial tem levado a um crescimento urbano intenso e desordenado das cidades, acelerando a degradação ambiental com o aparecimento de construções e ocupações irregulares do solo. Infelizmente, nas cidades brasileiras, a existência de moradias precárias e irregulares é comum, circunstância que compromete o princípio da dignidade da pessoa humana, previsto no artigo $1^{\circ}$, inciso II, da Constituição Federal de 1988.

O Poder Público deve empregar uma postura mais ativa e perene com as questões do direito à moradia, como direito social constitucional previsto pela Emenda Constitucional $n^{\circ}$ 26 de 2000. Com esta nova realidade jurídica, a política urbana habitacional foi alçada à política pública nacional, a ser executada pelos Municípios, com estratégia planejada e permanente, tendo como propósito central ordenar o desenvolvimento pleno das funções sociais das cidades, uma vez que a atuação insipiente ou incompleta nessa área reforça os problemas sociais, urbanos e ambientais.

A omissão do Poder Público no planejamento urbano e nas políticas públicas destinadas à valoração dos direitos fundamentais à moradia e ao meio ambiente ecologicamente equilibrado causa graves impactos socioambientais nas cidades. É notório o crescimento de assentamentos informais nos grandes centros urbanos, os quais resultam em quadros funestos e irrecuperáveis de degradação ambiental, diante da total transformação do espaço ocupado, alterando completamente a área originalmente existente.

Nas últimas décadas, a densidade demográfica das cidades aumentou rapidamente. $\mathrm{O}$ planejamento urbano, em contrapartida, não acompanha essa velocidade de crescimento demográfico, tornando-se incompatível com a garantia de uma moradia digna à população de baixa renda. 
Não bastasse isso, o Plano Diretor dos Municípios, enquanto componente básico da política de desenvolvimento e de expansão urbana, nem sempre observa as exigências locais específicas.

A obrigatoriedade de implantação do Plano Diretor apenas para as cidades com mais de vinte mil habitantes, além das outras hipóteses previstas no artigo 41 da Lei no 10.257 de 2001, parece desconsiderar a necessidade de os municípios menores ordenarem a cidade a partir de uma planificação e respeito às regras de uso e parcelamento do solo, em busca do cumprimento da função social da propriedade.

A importância de conciliar o direito à moradia e ao meio ambiente ecologicamente equilibrado encontra relevância na medida em que a garantia do bem-estar social do homem resulta no pleno desenvolvimento das funções sociais da cidade.

A compreensão dos conflitos socioambientais e fundiários não apenas como conflito coletivo, mas também como um problema social, no qual a sociedade como um todo deve ser chamada a participar, é elemento chave para que seja garantida a dignidade humana em cada situação, como também sejam trabalhadas as causas econômicas e políticas das ocupações de terra nas cidades.

A regularização fundiária é uma política pública que surge como resposta ao problema da falta de registro imobiliário em assentamentos irregulares nas cidades no Brasil.

Ter um diagnóstico municipal, conhecer melhor a dimensão jurídica da irregularidade daquela cidade, além de contar com um corpo de profissionais capacitados para a regularização fundiária, são questões importantes nesse sentido.

Em 2017, foi promulgada a Lei $n^{\circ} 13.465$, que dispõe sobre a regularização fundiária rural e urbana e prevê expressamente a adoção de meios extrajudiciais para a resolução de conflitos fundiários e para garantir o direito social à moradia digna (artigo 10, incisos V e VI).

Assim, diante desse cenário inovador, em que a legislação incentiva a desjudicialização dos conflitos fundiários, é que se desenvolverá a presente pesquisa.

$\mathrm{O}$ artigo contém abordagem qualitativa, com base descritiva e exploratória da temática, tendo sido realizada pesquisa bibliográfica para a elaboração do referencial teórico e dos resultados e discussões dispostos ao longo do trabalho.

Para uma melhor compreensão de como a pesquisa foi organizada, em primeiro lugar, realizou-se a contextualização sobre o tema escolhido, justificou-se a temática e foram dispostos os objetivos desse trabalho na presente introdução. Sequencialmente, foi estabelecido o referencial teórico contemplando o tópico sobre "O direito à moradia como Direito Humano e fundamental". 
Posteriormente, analisou-se "o direito fundamental à moradia e ao meio ambiente ecologicamente equilibrado" e "os conflitos socioambientais e fundiários urbanos". A seguir, estudou-se "a mediação como instrumento facilitador no processo de regularização fundiária". Finalmente, destacaram-se as considerações finais e referências utilizadas ao longo do artigo.

\section{O DIREITO À MORADIA COMO DIREITO HUMANO E FUNDAMENTAL}

Sarlet (2003) utiliza a expressão "Direitos Humanos Fundamentais" e sustenta não haver dúvidas de que os direitos fundamentais são também direitos humanos, pois o seu titular sempre será o ser humano, ainda que representados por entes coletivos, nações, povos, etc. Ressalta, ainda, que entre os dois termos, a expressão "direitos humanos" contém um contorno mais amplo e impreciso do que a expressão "direitos fundamentais", visto que estes constituem:

O conjunto de direitos e liberdades institucionalmente reconhecidos e garantidos pelo direito positivo de determinado Estado, tratando-se, portanto, de direitos delimitados espacial e temporalmente, cuja denominação se deve ao seu caráter básico e fundamentador do sistema jurídico do Estado de Direito (SARLET, 2003, pp. 33-35).

Cumpre esclarecer que os direitos fundamentais não são expressão sinônima de direitos humanos. Essa diferenciação é apresentada por Canotilho (2000, p. 387) que entende haver diferença efetiva entre as expressões "direitos do homem" e "direitos fundamentais", pois, segundo ele, a primeira são direitos válidos para todos em todos os tempos, enquanto que a segunda são aqueles direitos do homem, que estão, jurídico e institucionalmente, garantidos e limitados no espaço e no tempo.

Dessa forma, conclui-se que as expressões "direitos humanos" e "direitos fundamentais", apesar de serem utilizadas por muitos como sinônimas, não o são, pois apresentam significados diversos. E, apesar das diferenças terminológicas entre o direito humano e fundamental, pode-se afirmar que o direito à moradia é, verdadeiramente, um direito humano e fundamental, haja vista a referida modificação dos direitos fundamentais ao longo da história.

O direito à moradia, além de se tratar de direito fundamental e, por conseguinte, essencial ao cumprimento do princípio da dignidade humana, enquadra-se como instrumento para a efetivação de outros direitos sociais básicos, tais como a saúde, a educação, o trabalho, o lazer, entre outros. 
A Declaração Universal dos Direitos Humanos das Nações Unidas do ano de 1948 reconheceu pela primeira vez o direito à moradia - ainda que implicitamente - como integrante do rol dos direitos humanos ${ }^{87}$.

Em 1976, no Canadá, a Organização das Nações Unidas (ONU) promoveu a primeira Conferência das Nações Unidas sobre Assentamentos Humanos (Habitat I), em que, ao final, estabeleceu-se que não somente a moradia, mas a moradia adequada é um direito humano fundamental. Não se trata do estabelecimento de uma norma, mas de um princípio que deveria ser universalizado para a conquista da dignidade humana.

Em 1996, ocorreu a $2^{a}$ Conferência das Nações Unidas (Habitat II), em Istambul, na Turquia, que agregou ao direito de moradia adequada, temas globais e ambientais. Por sua vez, a ECO 92, Conferência das Nações Unidas sobre Meio Ambiente, realizada no Rio de Janeiro, em 1992, introduziu o conceito de sustentabilidade e este foi incorporado na Habitat II. Além disso, também foram inseridos temas importantes relacionados ao direito à moradia, como o papel da participação popular e a violação dos direitos humanos nos casos de retirada forçada de pessoas de suas habitações, face a vulnerabilidade social dos ocupantes, seja por conta de guerras, conflitos sociais e políticas estatais de renovação urbana, seja pela instalação de equipamentos públicos e modificação de zoneamentos.

A $3^{\text {a }}$ Conferência das Nações Unidas, Habitat III, aconteceu em 2016, em Quito, Equador. O tema central foi a igualdade de oportunidades para todos; o fim da discriminação; a importância das cidades mais limpas; a redução das emissões de carbono; o respeito pleno aos direitos dos refugiados e migrantes; a implementação de melhores iniciativas verdes e de conectividade, entre outras. O documento que orientará os Estados-membros a implementarem tais ações nos próximos vinte anos é a Nova Agenda Urbana.

Recentemente, em 2015, a Cúpula das Nações Unidas aprovou os Objetivos do Desenvolvimento Sustentável (ODS) a serem alcançados até 2030, elaborando plano de ação para o ser humano, o planeta e a prosperidade. A agenda consistiu numa Declaração com 169 (cento e sessenta e nove) metas e 17 (dezessete) objetivos, dentre os quais, impõe destacar o $\mathrm{n}^{\circ} 11$ :

Objetivo 11. Tornar as cidades e os assentamentos humanos inclusivos, seguros, resilientes e sustentáveis

\footnotetext{
${ }^{87}$ Artigo XXV. Todo ser humano tem direito a um padrão devida capaz de assegurar-lhe, e a sua família, saúde e bem-estar, inclusive alimentação, vestuário, habitação, cuidados médicos e os serviços sociais indispensáveis, e direito à segurança em caso de desemprego, doença, invalidez, viuvez, velhice ou outros casos deperda dos meios de subsistência em circunstâncias fora de seu controle.
} 
11.1 Até 2030, garantir o acesso de todos à habitação segura, adequada e a preço acessível, e aos serviços básicos e urbanizar as favelas.

A Constituição da República Federativa do Brasil de 1988 incluiu a dignidade da pessoa humana como princípio fundante da República enquanto Estado Democrático de Direito, de modo a conferir orientação para legitimar qualquer ação estatal, cuja funcionalidade segue como parâmetro central a preservação de tal fundamento em todos os seus aspectos.

Em outras palavras, cabe ao Estado proporcionar as condições mínimas para que os cidadãos alcancem a dignidade que lhes faça assegurar o pleno reconhecimento dos direitos fundamentais, como é o caso do direito à moradia. Vislumbra-se, aqui, a imprescindibilidade de um Poder Público intervencionista decorrente, inclusive, do Constitucionalismo Moderno e do Estado Social.

No mais, o artigo $6^{\circ}$ da Constituição Federal de 1988 prevê o direito à moradia como direito fundamental. Em razão de seu reconhecimento como direito humano, a moradia recebeu da ordem jurídica internacional um caráter inviolável e universal, que fez surgir na ordem jurídica interna a necessidade de elevá-lo à categoria de direito inerente a dignidade humana.

\section{O DIREITO FUNDAMENTAL À MORAdIA E AO MEIO AMBIENTE ECOLOGICAMENTE EQUILIBRADO}

É comum, nas cidades brasileiras, a existência de conflitos socioambientais decorrentes da ocupação ilegal de áreas de proteção ambiental.

Na maioria das vezes, a situação fática dos assentamentos irregulares situados em locais legalmente destinados à preservação do meio ambiente (áreas de preservação ambiental, reservas legais, 'áreas verdes' de loteamentos construídos por particulares) reveste-se de uma precariedade extrema, uma vez que, de um lado, a área não atende a sua função ambiental - porquanto ocupada por um expressivo número de pessoas com o fim de moradia -, e de outro, as famílias que residem sobre a área mantêm uma situação jurídica absolutamente irregular no tocante à ocupação fundiária, normalmente vivendo em condições indignas.

Desse modo, impõe-se que seja dada uma solução a essa questão, ou com a sua regularização fundiária, inclusive e em especial com a instalação de equipamentos urbanos, 
ou com a retirada destas famílias do local, para que a área volte a sua destinação original, qual seja: a de preservação da natureza. A manutenção da condição existente é manifestamente desaconselhável, uma vez que não atende de modo adequado nenhuma das funções que seria possível atribuir à área, isto é, a função social habitacional ou a função ambiental.

Isso faz com que a regularização fundiária exija uma maior e refletida atuação dos agentes municipais, até mesmo, em casos extremos, flexibilizando, no caso concreto, se necessário, os padrões de urbanização exigidos.

Deve ser ressaltado que tal flexibilização, caso utilizada, deve respeitar limites no que tange às situações de risco a que se encontrem expostas a população vulnerável socioeconomicamente, bem como garantir um mínimo de preservação ambiental.

Em síntese, é forçoso reconhecer que um dos maiores desafios da execução das políticas de regularização fundiária é a necessária harmonização entre o direito à moradia - e a segurança das populações - com o respeito ao meio ambiente ecologicamente equilibrado.

O direito ao meio ambiente equilibrado é previsto no artigo 225 da Constituição Federal de 1988, sendo dever da coletividade e do Poder Público preservá-lo às presentes e futuras gerações, de acordo, também, com o princípio da equidade intergeracional.

De um lado, há ocupações irregulares que, em si, representam grave degradação ambiental, mas que buscam o direito à moradia. Do outro, há a necessidade de preservação do meio ambiente.

Consequentemente, o Poder Público, quando da execução de projetos de regularização fundiária, enfrenta conflitos entre tais direitos fundamentais, cabendo ao seu executor o penoso desafio de verificar, no caso concreto, qual deles deve prevalecer.

Diante desse cenário, a busca do equilíbrio entre estas duas situações deve nortear todas as ações das políticas públicas relativas à questão habitacional, sendo um dos grandes desafios a serem enfrentados.

$\mathrm{Na}$ verdade, na maioria das situações, mostra-se muito mais conveniente a regularização de assentamentos habitacionais sem as mínimas condições de salubridade, mesmo que localizados em áreas ambientalmente protegidas por lei, uma vez que a degradação ambiental nestes locais é significativa e crescente.

Tais áreas, em geral, não guardam mais os requisitos que as fizeram necessárias à proteção do ecossistema como um todo. Uma área densamente ocupada, com todas as interações decorrentes (esgoto, produção de resíduos sólidos, destinação de águas servidas, impermeabilização do solo, etc.), não mais apresenta nenhuma das características que geraram a sua identificação normativa como sendo de importância ambiental. 
Diante disso, é mais vantajoso minorar os problemas causados pela ocupação humana, como, por exemplo, com a instalação de equipamentos urbanos básicos (tratamento de esgotos, recolhimento de lixo, etc.) e a conscientização dos ocupantes no sentido de minimizar as externalidades e os impactos ambientais.

Contudo, frequentemente a resposta estatal é baseada na inércia, que prefere não tomar nenhuma providência, seja no sentido de garantir a proteção ambiental, seja para assegurar o direito à moradia. Ademais, o custo financeiro e social desta alternativa pode ser proibitivo, pois o desfazimento de toda a ocupação pode trazer consequências ambientais e sociais bem piores do que a manutenção da ocupação urbana.

Assim sendo, inúmeras vezes, o Estado utiliza em sua defesa a Teoria da Reserva do Possível, isto é, alega a limitação orçamentária como forma de reduzir sua responsabilidade frente à garantia de direitos. Ocorre que o direito à moradia integra o mínimo existencial e, com efeito, o orçamento estatal deve ter como prioridade a implementação de tais direitos inerentes a dignidade humana. Veja-se o entendimento do Supremo Tribunal Federal (2011, p. 4):

\begin{abstract}
A cláusula da reserva do possível - que não pode ser invocada, pelo Poder Público, com o propósito de fraudar, de frustrar e de inviabilizar a implementação de políticas públicas definidas na própria Constituição - encontra insuperável limitação na garantia constitucional do mínimo existencial, que representa, no contexto de nosso ordenamento positivo, emanação direta do postulado da essencial dignidade da pessoa humana. [...] - A noção de "mínimo existencial", que resulta, por implicitude, de determinados preceitos constitucionais (CF, art. $1^{\circ}$, III, e art. $3^{\circ}$, III), compreende um complexo de prerrogativas cuja concretização revela-se capaz de garantir condições adequadas de existência digna, em ordem a assegurar, à pessoa, acesso efetivo ao direito geral de liberdade e, também, a prestações positivas originárias do Estado, viabilizadoras da plena fruição de direitos sociais básicos, tais como o $[\ldots]$ o direito à moradia $[\ldots]$.
\end{abstract}

Em outras palavras, o Poder Público não pode abster-se de efetivar o direito à moradia, uma vez que é a base para o desenvolvimento de uma vida pautada na dignidade. Arrisca-se dizer que é, inclusive, o mais primordial dos direitos sociais, haja vista que não há o que se falar em outros direitos fundamentais, como o direito à saúde, à educação, ao lazer, se sequer um lar é garantido aos indivíduos vulneráveis socioeconomicamente.

Mormente, observa-se que até mesmo com relação à limitação de uso decorrente das áreas de preservação permanente reguladas pelo Código Florestal há a possibilidade de mitigação de tais regras, conforme dispõe o artigo $3^{\circ}, \S 1^{\circ}$, e artigo $4^{\circ}$, ambos da Lei $n^{\circ}$ 4.771/65 (redação dada pela Medida Provisória 2.166-67/2001), o qual admitiu a supressão de 
vegetação em tais áreas, desde que autorizada pela autoridade competente e em casos de utilidade pública ou interesse social.

É cristalino que as situações de regularização fundiária se enquadram, perfeitamente, na exigência básica para a supressão total ou parcial da área de preservação permanente, qual seja: a caracterização de situação de utilidade pública ou interesse social.

Em complemento a tal permissivo legal, o Conselho Nacional do Meio Ambiente (CONAMA) editou a Resolução $n^{\circ} 369 / 06$, a qual fixou parâmetros a partir dos quais é possível a autorização da regularização fundiária de ocupações de áreas de preservação permanente, pelo órgão ambiental competente, desde que os critérios objetivos e requisitos ambientais mínimos sejam preenchidos (CONAMA, 2006). Tais normas visam a possibilitar a regularização de situações consolidadas em que a reversão ao statu quo ante não seja viável.

\section{OS CONFLITOS SOCIOAMBIENTAIS E FUNDIÁRIOS URBANOS}

Os conflitos socioambientais caracterizam-se por terem uma natureza em constante mudança e evolução, podendo ocorrer em vários contextos, como quando da violação ao meio ambiente natural, artificial, urbano, do trabalho e outros.

Ao analisar o conflito socioambiental, é imprescindível verificar a problemática sob o prisma das relações sociais. A questão ambiental analisada sob essa orientação põe no centro do debate as diferentes práticas sociais, relativizando a noção de meio ambiente, que deixa de ser tomada unilateralmente, para ser compreendida na complexidade das situações apresentadas e vivenciadas pelos diversos agentes sociais que dele se apropriam.

Nesse sentido, o conflito socioambiental apresenta-se como um conflito social que expressa as relações entre interesses coletivos versus interesses privados e espaço público versus tentativa de apropriação de espaço público. Yaghsisian, Freitas e Cardoso (2018, p. 97) destacam algumas das características desses conflitos:

Os conflitos ambientais têm algumas características, como uma forte carga social e grande complexidade, pois os interesses sociais muitas vezes se chocam com os interesses públicos e envolvem múltiplos fatores e atores, com uma dinâmica que nem sempre é previsível.

Um dos principais conflitos socioambientais, pois envolvem um alto conteúdo social e ambiental, são os que surgem no meio ambiente urbano, em torno do uso e ocupação do solo. Comumente surgem com as necessidades habitacionais, cuja consequência é a descontrolada ocupação ilegal do solo urbano. 
Nas áreas urbanas, os conflitos socioambientais referem-se à equidade social. No espaço rural, os conflitos socioambientais referem-se à apropriação dos recursos naturais, como terra, floresta e água, ou a preservação de culturas envolvendo as populações tradicionais, como os povos indígenas, remanescentes de quilombos, ribeirinhos, povos da floresta e outros.

A definição de conflitos fundiários urbanos foi trazida pelo Ministério das Cidades no artigo $3^{\circ}$, I da Resolução recomendada ${ }^{\circ} 87$ do Conselho das Cidades, de 8 de dezembro de 2009, nos seguintes termos:

Disputa pela posse ou propriedade de imóvel urbano, bem como impacto de empreendimentos públicos e privados, envolvendo famílias de baixa renda ou grupos sociais vulneráveis que necessitem ou demandem a proteção do Estado na garantia do direito humano à moradia e à cidade.

Outrossim, embora diversos diplomas legais previstos no ordenamento jurídico pátrio prevejam formas de efetivar a regularização fundiária no que tange à população de baixa renda, em especial o Estatuto da Cidade (Lei n $\left.{ }^{\mathbf{0}} 10.257 / 01\right)^{\mathbf{8 8}}$, não se verifica nenhum esforço do Poder Público em implementá-las e, por conseguinte, em garantir a dignidade humana.

Afinal, o Estado permanece inerte frente às políticas habitacionais e assistenciais, o que leva as pessoas vulneráveis economicamente a ocuparem áreas irregularmente, colocando em risco, até mesmo, suas próprias vidas.

Segundo Martino e Freitas (2018, p.67):

[...] o processo de ocupação irregular, fruto da urbanização acelerada no Brasil, ocorre em inúmeras cidades, especialmente as metrópoles, haja vista que as ofertas em relação à economia, emprego e infraestrutura são superiores. Contudo, o acesso da população mais vulnerável socioeconomicamente a esses equipamentos públicos e sociais não atende às suas expectativas. Ou seja, não raras vezes, a baixa remuneração - ou, até mesmo, o trabalho informal - não possibilita que tal parte da população alcance a formalidade no que tange à moradia, além de limitá-la às áreas periféricas e, inclusive, às áreas passíveis de desastres ambientais.

Além de serem invisíveis pela sociedade e pelo Poder Público, haja vista terem seus direitos fundamentais violados constantemente, sofrem estigmas, o que contribui ainda mais com a segregação socioespacial, com a dificuldade de inserção no mercado de trabalho formal e com a participação na comunidade.

É notório tal assertiva, ao verificar-se o estudo realizado por Caldeira (2011, p. 31), ao entrevistar uma moradora da Mooca/São Paulo:

\footnotetext{
${ }^{88}$ Ressalte-se que o Estatuto da Cidade, em seu artigo 10, caput, prevê a aquisição da propriedade por meio de usucapião coletivo em caso da existência de núcleos urbanos informais há mais de cinco anos, bem como posse mansa e pacífica e cuja a área total dividida pelo número de possuidores seja inferior a $250 \mathrm{~m}^{2}$, desde que os possuidores não sejam proprietários de outro imóvel urbano ou rural.
} 
Se você soubesse o que o meu marido fala quando passa em frente a uma favela! Ele é tão revoltado! Eu também. [...] O meu marido, você não sabe o que ele fala. Ele vê um cortiço, uma favela, fala que uma garrafa de querosene e um fósforo resolvia aquilo num minuto [...] Mas a turma é indolente também, não quer saber de trabalhar. Pior é favela, bandido tá dentro de favela.

Mormente, de acordo com Smolka (2003), a informalidade é causa e efeito da pobreza. Isto porque a ausência do direito à moradia, que leva as pessoas aquém da linha da miséria e de qualquer dignidade, e a ausência de controle informal contribui, ainda mais, para a violação de outros direitos (como o direito à saúde, educação, ao trabalho, ao saneamento básico, à arquitetura sustentável, à água, etc.) e, por conseguinte, torna os ocupantes ainda mais pobres.

É necessário mencionar aqui, com cautela no afã de não corroborar com a falsa ideia de criminalização absoluta da pobreza, a possibilidade das ocupações irregulares, fruto do resultado acelerado da urbanização segregadora e da omissão do Poder Público, serem vetores criminológicos, uma vez que os ocupantes, sem qualquer perspectiva de melhora no futuro, acabam vendo oportunidades no crime organizado.

Não obstante, não raras vezes os legitimados para o ajuizamento de ação civil pública $^{\mathbf{8 9}}$ requerem judicialmente a retirada dos ocupantes dessas áreas, o que é deferido pelo juízo, já que não há nenhuma análise da dignidade humana e da possibilidade fática do cumprimento da sentença. Busca-se tão somente a obedecer ao texto legal.

Na prática, não há qualquer efeito. Ou pior: tais pessoas são retiradas coercitivamente e violentamente, mediante uso da força policial, sem que haja qualquer processo de recolocação efetivo.

De acordo com o exposto, há a conclusão de uma pesquisa realizada pelo Centro de Estudos sobre o Sistema de Justiça do Ministério da Justiça (BRASIL, 2013, s.p.):

Apesar da consolidação no ordenamento jurídico brasileiro do direito à moradia
digna como uma garantia social, apesar dos princípios, diretrizes e regras emanadas
do Estatuto da Cidade e das resoluções advindas do Conselho Nacional das Cidades,
o Poder Judiciário, na maioria dos casos, privilegia a aplicação da legislação civil e
processual civil para determinar a desocupação liminar e, por vezes, com uso de
força policial das áreas submetidas a disputa.

Em outras vezes, o Poder Judiciário reconhece o direito à moradia como o mínimo existencial e, assim, reafirma o dever e a responsabilidade do Estado em garanti-lo. Contudo,

\footnotetext{
${ }^{89}$ São legitimados para ajuizar ação civil pública: Administração Pública Direta e Indireta, Ministério Público, Defensoria Pública e associações civis constituídas há, pelo menos, um ano, desde que possuam pertinência temática (artigo $5^{\circ}$ da Lei $n^{\circ} 7.347 / 85$ ).
} 
embora não admitido pelo Supremo Tribunal Federal, o Poder Público, em sua defesa, alega a Teoria da Reserva do Possível e não adota nenhuma medida nesse sentido.

Ou seja, em qualquer uma das possibilidades da resposta do Judiciário frente a essa problemática, não há uma mudança substancial no sentido de cumprir os direitos fundamentais.

Nota-se, portanto, que os conflitos fundiários não se limitam a judicialização da questão. Eles vão muito além: precisam de medidas eficazes, os envolvidos precisam ser ouvidos e respeitados, deve-se encontrar uma solução pautada na proporcionalidade e na isonomia em relação aos envolvidos, sem que haja, dessa forma, influência do poder econômico ou político da Administração Pública, o que é possível por meio da mediação.

Nesse diapasão, Trombini et al. (2004, p. 9):

[...] é necessário evidenciar uma das premissas do estudo, a de que o Poder Judiciário encontra uma série de limitações para a resolução de conflitos coletivos pela terra. Frequentemente o próprio Estado figura como principal violador de direitos e, por ação ou omissão, acirra as desigualdades no acesso à moradia de sujeitos já em situação de desigualdade. Nas cidades, os ônus e os bônus da urbanização são distribuídos de forma desigual, e a palavra de ordem dos movimentos sociais é "quando morar é um privilégio, ocupar é um direito". A emergência de conflitos coletivos pela terra urbana e episódios de despejos violentos desafiam os limites das soluções jurídicas do problema. As decisões do Judiciário ora transferem à polícia a responsabilidade por levar a cabo o cumprimento da ordem, ora ao Poder Executivo a responsabilidade de atender as necessidades materiais em discussão. Seja como for, fracassam na oferta de soluções ao conflito e ignoram o papel do Poder Público no atendimento ao direito à moradia, garantido constitucionalmente.

Como efeito, o Governo Federal editou o Decreto n ${ }^{\circ}$ 7.037/09 com o fim de aprovar o Programa Nacional de Direitos Humanos (PNDH-3), convidando os Poderes Judiciário, Executivo, Legislativo e o Ministério Público a aderi-lo, o qual prevê medidas específicas no tocante à mediação de conflitos urbanos fundiários ${ }^{90} \mathrm{e}$ as seguintes ações programáticas nesse tema:

a) fomentar iniciativas de mediação e conciliação, estimulando a resolução de conflitos por meios autocompositivos, voltados à maior pacificação social e menor judicialização. b) fortalecer a criação de núcleos de justiça comunitária, em articulação com os Estados, o Distrito Federal e os Municípios, e apoiar o financiamento de infraestrutura e de capacitação. c) capacitar lideranças comunitárias sobre instrumentos e técnicas de mediação comunitária, incentivando a resolução de conflitos nas próprias comunidades. d) incentivar projetos pilotos de Justiça Restaurativa, como forma de analisar seu impacto e sua aplicabilidade no sistema jurídico brasileiro. e) estimular e ampliar experiências voltadas para a solução de conflitos por meio da mediação comunitária e dos Centros de Referência

90 É o processo envolvendo as partes afetadas pelo conflito, instituições e órgãos públicos e entidades da sociedade civil vinculados ao tema, que busca a garantia do direito à moradia digna e adequada e impeça a violação dos direitos humanos. (artigo $3^{\circ}$ da Resolução $n^{\circ} 87$ do CONCIDADES). 
em Direitos Humanos, especialmente em áreas de baixo Índice de Desenvolvimento Humano (IDH) e com dificuldades de acesso a serviços públicos.

Outrossim, a Resolução Recomendada $n^{\circ}$ 87/09 recomendou ao Ministério das Cidades instituir a Política Nacional de Prevenção e Mediação de Conflitos Fundiários Urbanos, o qual fixa os objetivos, diretrizes e princípios específicos da mediação quando aplicada nesse contexto.

Diante de todo o exposto, observa-se que a mediação, quando utilizada nos conflitos urbanos fundiários, é um aliado importante no afã de garantir os direitos humanos, o acesso à Justiça, ao julgamento célere, dar visibilidade e empoderamento aos ocupantes, respeitar seus direitos e seu local de fala, dar tratamento isonômico aos participantes, encontrar uma solução razoável, adequada e justa para todos, além de contribuir para o não sucateamento do Poder Judiciário.

Vislumbra-se que a ideia dos meios autocompositivos relaciona-se com a liberdade dos indivíduos, ao contrário da imposição estatal, por meio da jurisdição, de uma decisão. Assim, Sen (2017, p. 291) esclarece: “A solução do problema da população requer mais liberdade, e não menos".

Assim, a solução do conflito através da negociação direta entre as partes, através de um modelo cooperativo e integrativo, dá ênfase a ganhos mútuos para todos os envolvidos.

\section{A MEdiAÇÃo COMO INSTRUMENTO FACILITADOR NO PROCESSO DE REGULARIZAÇÃO FUNDIÁRIA}

É indiscutível o número excessivo de processos judiciais que tramitam no Brasil, o que torna extremamente necessário a discussão a respeito de novas alternativas em substituição ao litígio judicial com intuito de garantir o efetivo direito de acesso à justiça e à celeridade processual.

No entanto, ainda há muito a ser implementado no sentido de fazer com que a sociedade aceite meios baseados na solução pacífica dos conflitos, já que há uma resistência nesse sentido, perpetrada, até mesmo, pelos advogados.

É o que explica Faleck (2018, p. 10): "Mesmo assim, os números da justiça brasileira demonstram que a opção pelo litígio tem sido preponderantemente utilizada pelo cidadão brasileiro. A atividade estatal tem tido o papel central na solução das disputas, realização da Justiça e harmonização social". 
Tais métodos consensuais possuem inúmeros benefícios, uma vez que permitem maior participação das partes na busca por uma decisão mais justa e eficiente para si, além de evitarem o congestionamento do Poder Judiciário com causas que poderiam ser facilmente resolvidas por outros meios. Nota-se, então, a importância dos meios de autocomposição, como é o caso da mediação.

Como requisitos dos meios autocompositivos, é necessário que as partes sejam capazes, que os direitos sejam disponíveis e que haja consenso.

Ressalte-se que a disponibilidade do direito refere-se tão somente a maneira pelo qual ele será exercido. Isto é, é perfeitamente possível que um direito indisponível seja objeto de autocomposição, já que não ocorrerá sua renúncia. Em outras palavras, por exemplo, o direito aos alimentos trata-se de um direito indisponível. Contudo, é possível a celebração de acordo no que tange à forma pela qual a obrigação alimentar será cumprida (isto é, por meio de pagamento em dinheiro, plano de saúde, escola, etc.). Assim sendo, caso se trate de direito indisponível, é imprescindível a homologação do acordo em juízo, ouvido o Ministério Público (artigo $3^{\circ}, \S 2^{\circ}$, Lei no $\left.13.140 / 15\right)$.

Mormente, é importante que se diferencie a conciliação da mediação. A conciliação é indicada para as partes que não possuem vínculo anterior, como é o caso, por exemplo, de sujeitos envolvidos em acidente de trânsito. Aqui, o conciliador é mais propositivo e apresenta possíveis soluções às partes. A mediação, por outro lado, é adequada aos sujeitos com vínculo anterior (por exemplo: litígios familiares). Por isso, o mediador é um ouvinte ativo, não apresentando propostas, mas sim ajudando os envolvidos a delimitarem o conflito e, assim, eles mesmos são quem encontram um desfecho.

Vasconcelos (2012, p.42) ensina:

\begin{abstract}
A Mediação é um meio geralmente não hierarquizado de solução de disputas em que duas ou mais pessoas, em ambiente seguro e de serenidade, com a colaboração de um terceiro, o mediador- que deve ser apto, imparcial, independente e livremente escolhido ou aceito-, expõem o problema, são escutadas e questionadas, dialogam construtivamente e procuram identificar os interesses comuns, opções e, eventualmente, firmar um acordo.
\end{abstract}

Em relação à legislação, o antigo Código de Processo Civil de 1973 previa a possibilidade da conciliação nas ações regidas pelo procedimento sumário em momento anterior à apresentação da defesa do réu em audiência, bem como nas ações de procedimento ordinário, após o decurso do prazo para a defesa por designação judicial. No mais, a Lei ${ }^{\circ}$ 9099/95, que dispõe sobre os Juizados Especiais Cíveis e Criminais, também prevê e permite a conciliação. Posteriormente, a Resolução $n^{\circ}$ 125/10 do Conselho Nacional de Justiça 
estabeleceu a Política Judiciária Nacional de tratamento adequado dos conflitos de interesses no âmbito do Poder Judiciário e, por conseguinte, tratou da possibilidade de aplicação dos métodos consensuais, como mediação e conciliação, em substituição aos processos judiciais litigiosos, haja vista a política de pacificação social.

O Novo Código de Processo Civil, por sua vez, privilegiou e incentivou a implantação e aplicação dos meios alternativos de solução de conflitos. Afinal, em seu artigo $3^{\circ}$, § $2^{\circ}$ e $3^{\circ}$, determina que é dever do Estado promover tais meios, além de prever que os juízes, promotores, defensores públicos e advogados devem incentivá-los, inclusive durante o processo judicial. Outrossim, o artigo 334, caput, do referido diploma legal menciona que se a petição inicial preencher os requisitos essenciais e não for o caso de improcedência liminar do pedido, o juiz deve designar audiência de conciliação ou mediação. Tal audiência poderá ser realizada até mesmo por meio eletrônico. Veja-se que o não comparecimento injustificado das partes à audiência de conciliação/mediação configura ato atentatório à dignidade da justiça e, por isso, sujeito a pena de multa, no valor de até $2 \%$ (dois por cento) da vantagem econômica pretendida ou do valor da causa, revertida em favor da União ou do Estado.

Ressalte-se que, segundo o artigo 784, inciso IV, do mesmo diploma legal, o instrumento de transação se referendado pelo Ministério Público, pela Defensoria Pública, pela Advocacia Pública, pelos advogados dos transatores ou por conciliador ou mediador credenciado por tribunal terá eficácia de título executivo extrajudicial, o que, per si, demonstra o privilégio dos meios alternativos no Novo Código de Processo civil.

Destaca-se que é vedado qualquer tipo de constrangimento ou intimidação para que as partes participem de conciliação/mediação. Não há obrigatoriedade.

Ademais, o Código de Processo Civil prevê que nas ações de família, deve-se depreender todos os esforços necessários no afã de que se alcance a solução consensual do conflito, de acordo com o artigo 694.

Destarte, a Lei $n^{\circ} 13.140 / 15$, que previu e detalhou os procedimentos de aplicação da mediação e conciliação, possibilitou a participação da Administração Pública frente aos meios alternativos de solução de conflito.

A mediação poderá, ainda, versar sobre todo o conflito ou apenas sobre parte dele.

Observa-se que a mediação segue os princípios da imparcialidade do mediador, da isonomia entre as partes, da oralidade, informalidade, autonomia da vontade das partes, busca do consenso, confidencialidade e boa fé ( $\operatorname{artigo} 2^{\circ}$ da Lei $\left.n^{\circ} 13.140 / 15\right)$. 
Há, também, diversos modelos de procedimentos de mediação conforme preveem as diferentes Escolas, quais sejam: Escola Tradicional Linear, Escola Transformativa e Escola Circular Narrativa.

Para Yaghsisinian, Freitas e Cardoso (2018), a primeira fundamenta-se na comunicação para a resolução de conflitos e tem como objetivo elaborar um acordo com ganhos para ambas as partes, bem como diminuir as diferenças através de uma comunicação eficiente. No mais, o mediador possui menor intervenção e não emite opinião. É indicada para os conflitos de média ou alta complexidade, desde que não se pretenda manter os vínculos entre os envolvidos.

A Escola Transformativa, por outro lado, possui como base a reflexão na tomada de decisões e como finalidade a transformação das relações humanas e não o acordo por si só. Tal modelo é indicado para as partes que possuem grande vínculo.

Por último, a Escola Circular Narrativa tem como pressuposto a mudança das histórias individuais a fim de transformá-la em uma história comum. A priori, busca-se uma compreensão compartilhada do conflito. Logo, o acordo não é a prioridade. É apontado como eficiente para as causas com grande complexidade em que as partes possuam vínculo permanente e duradouro.

No que tange aos conflitos fundiários urbanos, segundo o artigo $3^{\circ}$, inciso III, da Resolução Recomenda $n^{\circ}$ 87, do Conselho das Cidades, a mediação é um procedimento que envolve as partes afetadas pelo conflito, instituições, órgãos públicos e entidades da sociedade civil vinculados ao conflito, em direção à garantia do direito à moradia digna e adequada, além de impedir a violação dos direitos humanos.

Tal meio alternativo privilegia a resolução pacífica e de benefício mútuo, mostrandose em harmonia com a contemporânea visão de direitos fundamentais e interdisciplinaridade que permeia o ramo do Direito Urbanístico. Nesse sentido, a dinâmica da mediação adapta-se aos novos tempos, tratando-se de um meio eficaz para resolução de conflitos (BRASIL, 2013).

Destarte, a Resolução Recomenda $\mathrm{n}^{0} 87$ não limita os atores participantes. Ao contrário, permite que os órgãos públicos e as entidades da sociedade civil que sejam afeitos à temática ou ao conflito possam atuar como agentes de interlocução política, dentre eles, a Defensoria Pública, os movimentos sociais, o Ministério Público, o Poder Executivo, entre outros.

As diretrizes impostas aos poderes públicos, quanto à regularização fundiária, são no sentido de que as ações devem respeitar os princípios de sustentabilidade econômica, social e 
ambiental, efetivando no âmbito político e administrativo o princípio da equidade intergeracional.

Recentemente, em 2017, foi publicada a Lei $\mathrm{n}^{\circ} 13.465$, que dentre alguns objetivos gerais da regularização fundiária a serem observados pela União, Estados, Distrito Federal e Municípios, traz a integração social e a geração de emprego e renda; a garantia do direito social à moradia digna; efetivação da função social da propriedade e da cidade e, quanto ao tema de resolução de conflitos, expressou a necessidade de estimular a sua resolução extrajudicial, em reforço ao consenso e à cooperação entre Estado e sociedade.

A previsão expressa no artigo 21 da Lei 13.465/2017 é de que, diante de impugnação do procedimento de regularização fundiária, pode ser adotado procedimento extrajudicial de composição de conflitos abre caminho para adoção da mediação, que observará o disposto na Lei $\mathrm{n}^{\circ} 13.140$, de 26 de junho de 2015 ( $\$ 3^{\circ}$ do artigo 21), o que fortalece a ideia de que a tal meio alternativo quando aplicado aos conflitos fundiários promove um processo decisório democrático e participativo:

\footnotetext{
Artigo 21 - Na hipótese de apresentação de impugnação, poderá ser adotado procedimento extrajudicial de composição de conflitos.

$\S 3^{\circ}$ - A mediação observará o disposto na Lei no 13.140, de 26 de junho de 2015, facultando-se ao poder público promover a alteração do auto de demarcação urbanística ou adotar qualquer outra medida que possa afastar a oposição do proprietário ou dos confrontantes à regularização da área ocupada.
}

Para garantir uma igualdade de participação na construção das soluções, o ideal é que a tentativa de resolução do conflito socioambiental e fundiário ocorra dentro de um procedimento de mediação, conciliação ou negociação a fim de garantir os interesses individuais e ambientais.

A proposta de uma metodologia da mediação que seja inclusiva, pedagógica, transformadora e emancipadora traz um novo horizonte para as questões da cidade e os modos de solucioná-las. Para além da resolução de conflitos por via do diálogo e da intercompreensão, o método da mediação comunitária visa a um efetivo resgate dos direitos humanos em comunidades marginalizadas, como explicita Gustin (2005, p. 207):

O resgate dos direitos humanos em localidades de extrema exclusão (favelamentos) e de periferias e, inclusive, de países também periféricos, exige que seja atribuída às populações dessas localidades o status de sujeito de sua própria história, no interior de um processo pedagógico edificante e emancipador. Há que se instaurar um processo onde as pessoas tornam-se atores conscientes de sua exclusão e de seus riscos e danos e das suas possibilidades de solução. Só assim, e exclusivamente assim, é que a adversidade pode ser superada ou minimizada. 
Segundo Souza (2012, pp. 93-102), a mediação é o método de resolução de conflitos mais apropriado para solucioná-los, pois o procedimento permite que todos os interessados, envolvidos direta ou indiretamente no conflito, possam participar na busca por uma solução consensual melhor para todos. A mediação busca encurtar a distância existente entre a Justiça e a sociedade, incentivando os cidadãos a atuarem de forma efetiva na solução dos conflitos, atendendo assim suas necessidades.

Ademais, a mediação exige uma visão multidisciplinar do problema, envolvendo profissionais de áreas diferentes que possam, de forma mais célere, contribuir para a resolução de tais conflitos, já que resumir o debate no antagonismo de interesses exclusivamente sob a ótica do discurso jurídico pode acarretar na não solução do caso ante a complexidade de tais demandas.

\section{CONSIDERAÇÕES FINAIS}

É latente a necessidade de buscar outros meios de solução dos litígios, que não por meio do Poder Judiciário, haja vista o volume exacerbado de processos existentes em trâmite. Com efeito, surgiram os meios alternativos de solução de conflitos, como a mediação.

A mediação, conforme exposto, visa o fim da disputa por meio do consenso entre os envolvidos. Isto é, as partes possuem oportunidade de serem ouvidas e de encontrarem uma solução possível que pensarem ser mais justa ao caso concreto.

Em que pese a participação do mediador, este não impõe sua opinião e tampouco uma decisão. Pelo contrário, apenas apresenta possíveis soluções para que as próprias partes estabeleçam a que julgarem mais adequada.

Diante disso, nota-se que há um tratamento isonômico entre os envolvidos, afastando qualquer posição de vulnerabilidade ou de poder econômico/político, sendo extremamente importante nos conflitos que envolverem, especialmente, o Poder Público e a população de baixa renda, como ocorre nos conflitos fundiários urbanos.

Vislumbrou-se que as ações civis que versam sobre a retirada dos ocupantes de áreas irregulares não possuem nenhum efeito prático e muito menos respeitam os direitos humanos, considerando a retirada violenta e coercitiva perpetrada pela polícia como forma de cumprir a decisão judicial e a ausência de processos de recolocação efetivos. Por outro lado, quando o Poder Judiciário reconhece o direito à moradia e ratifica o dever do Estado em fornecer moradia, este permanece inerte. 
Concluiu-se, portanto, que a mediação é um aliado essencial no sentido de garantir as liberdades individuais, os direitos sociais, o que inclui o direito à moradia, e a participação da população vulnerável na tomada de decisões frente ao Poder Público.

No mais, os benefícios dos meios autocompositivos são inúmeros, como o não sucateamento do Judiciário, o melhor cumprimento do acordo em relação à decisão do magistrado, haja vista que são as próprias partes que a fixam, a humanização dos envolvidos e uma solução mais justa e exequível.

Por fim, conforme apresentado, é juridicamente possível a aplicação de tais meios. E mais: a própria legislação determina que devem ser incentivados e implementados pelo Estado.

Diante do exposto, a mediação é um meio apto a conferir à parcela social não raras vezes marginalizada, residente nessas ocupações, o status de emancipação e empoderamento no que tange à defesa de seus direitos em meio aos conflitos urbanos, além de viabilizar a democracia participativa e a pacificação da sociedade.

Finalmente, destaca-se que não é o intuito do presente artigo exaurir a temática da mediação como instrumento de pacificação social no âmbito da regularização fundiária, sugerindo-se, dessa forma, que outras pesquisas sejam elaboradas a partir do que aqui foi exposto, podendo, ainda, ser utilizado como fonte de análise para avaliações futuras com estudos de casos concretos múltiplos.

\title{
REFERÊNCIAS
}

- Mediação de Conflitos Fundiários Urbanos: do Debate Teórico à Construção Política. In: Revista da Faculdade de Direito UniRitter, nº 11. Porto Alegre, 2010.

\author{
BRASIL. CENTRO DE ESTUDOS SOBRE O SISTEMA DE JUSTIÇA. Soluções \\ alternativas para conflitos fundiários urbanos. 2013. Disponível em: \\ $<$ http://www.justica.gov.br/seus-direitos/politicas-de- \\ justica/publicacoes/Biblioteca/dialogossobrejustica_atuacao_-nos- \\ conflitos_fundiarios_urbanos.pdf/>. Acesso em 05 dez. 2018.
}

CAFRUNE, Marcelo. Mediação de Conflitos Fundiários Urbanos: do Debate Teórico à Construção Política. Revista da Faculdade de Direito UniRitter, 2010. Disponível em: $<$ http://www.suelourbano.org/wp-content/uploads/2017/08/CAFRUNEMedia\%C3\%A7\%C3\%A3o-de-Conflitos-Fundi\%C3\%A1rios-Urbanos-do-DebateTe\%C3\%B3rico-\%C3\%A0-Constru\%C3\%A7\%C3\%A3o-Pol\%C3\%ADtica.pdf> Acesso em 05 dez. 2018 
CALDEIRA, Teresa Pires do Rio. Cidade de muros: crime, segregação e cidadania em São Paulo. $3^{\text {a }}$ ed. São Paulo: Editora 34, 2011.

CANOTILHO, Gomes. Direito Constitucional. 4ª ed. Coimbra: Livraria Almedina, 2000.

CONAMA. Resolução $\mathbf{n}^{\mathbf{0}} \mathbf{3 6 9 / 0 6}$ 2006. Disponível em: $<$ http://www2.mma.gov.br/port/conama/legiabre.cfm?codlegi=489>. Acesso em 20 ago. 2019.

FALECK, Diego. Manual de design de sistemas de disputas. Rio de Janeiro: Lumes Juris, 2018.

GUSTIN, Miracy Barbosa de Souza. Resgate dos direitos humanos em situações adversas de países periféricos. In: Revista da Faculdade de Direito, nº 47. Belo Horizonte, 2005.

MARTINO, I. R. L.; FREITAS, G. P. Direito à moradia: ocupações irregulares em áreas de preservação permanente (APP). Revista Querubim (Online), v. Especial, p. 61-75, 2018.

<http://www.revistaquerubim.uff.br/images/arquivos/zseo_especial_2018_mayara.pdf?fbclid =IwAR112hhy1UBEQ3X2OoxzhBIt39LPwzk7qmLKm3VCzOQZy8QWhR4HKiZjki8>.

Acesso em 05 dez. 2018.

MINISTÉRIO DA JUSTIÇA. Secretária de Reforma do Judiciário. Diálogos sobre justiça: soluções alternativas para conflitos fundiários urbanos. Brasília, 2013, p. 45.

SARLET, Ingo Wolfgang. A Eficácia dos Direitos Fundamentais. $3^{\text {a }}$ ed. Porto Alegre: Livraria do Advogado, 2003.

SEN, Amartya. Desenvolvimento como Liberdade. São Paulo: Companhia das Letras, 2017.

SMOLKA, Martim. Regularização da ocupação do solo urbano: a solução que é parte do problema, o problema que é parte da solução. In: FERNANDES, Edésio; VEZZULLA, Juan Carlos. Teoria e prática da mediação. Curitiba: Instituto de Mediação e Arbitragem do Brasil, 1998.

SOUZA, Luciane Moessa. Mediação de conflitos coletivos. Belo Horizonte: Editora Fórum, 2012, p. 93-102. 
TROMBINI, M et al. Diálogos sobre justiça e conflitos fundiários urbanos: caminhando da mediação para a efetivação dos Direitos Humanos. 2017. Disponível em: $<$ https://terradedireitos.org.br/uploads/arquivos/Terra-de-Direitos_DIALOGOS-SOBREJUSTICA_270717_web-(1).pdf>. Acesso em 4 dez. 2018.

VASCONCELOS, Carlos Eduardo de. Mediação de conflitos e práticas restaurativas. São Paulo: Método, 2012.

YAGHSISIAN, Adriana Machado; FREITAS, Gilberto Passos de; CARDOSO, Simone Alves. Mediação - Instrumento de cidadania e pacificação. Santos: Editora Universitária Leopoldianum, 2018.

SUPREMO TRIBUNAL FEDERAL. Ag.Reg. No recurso extraordinário com agravo 639.337 São Paulo. 2011. Disponível em: http://redir.stf.jus.br/paginadorpub/paginador.jsp?docTP=AC\&docID=627428. Acesso em 21 ago. 2019.

\title{
MEDIATION AS AN INSTRUMENT OF SOCIAL PACIFICATION IN LAND URBAN CONFLICTS
}

\begin{abstract}
This article deals with urban land conflicts where, as a rule, the right to housing and, on the other hand, the right to the environment ecologically balanced, both guaranteed by various treaties signed by Brazil, as well as by the Federal Constitution. Considering that there is a serious need to weigh up these rights in this case, the possibility of applying the institute for the mediation of such conflicts was analyzed, especially in the context of land regularization in order to ensure a more reasonable and just solution for all involved. Regarding the methodological procedures, this research had a qualitative approach, based on descriptive and exploratory character, and a bibliographical survey was carried out to prepare the theoretical contribution made throughout the work. Finally, it has been found that such an alternative means of conflict resolution is essential for guaranteeing the fundamental rights in question.
\end{abstract}

Keywords: Mediation. Land regularization. Housing. Environment. 